\title{
Third-Order Nonlinear Optical Properties of DA-salen-Type Nickel(II) and Copper(II) Complexes
}

\author{
João Tedim, ${ }^{[a l[\$]}$ Sónia Patrício, ${ }^{[a]}$ Rosa Bessada, ${ }^{[a]}$ Rui Morais, ${ }^{[b, c]}$ \\ Carla Sousa, ${ }^{[a] l+\neq 1}$ Manuel B. Marques, ${ }^{[b, c]}$ and Cristina Freire ${ }^{*[a]}$
}

Keywords: Third-order NLO properties / Z-scan technique / UV/Vis spectroscopy / Schiff bases

\begin{abstract}
Third-order nonlinear and linear optical properties of nickel(II) and copper(II) complexes with salen ligands, functionalised with electron donor/acceptor groups (DA-salen), have been investigated in solution by the Z-scan technique using an Nd:YAG laser $\left(\lambda_{\text {inc }}=1064 \mathrm{~nm}\right)$ and UV/Vis spectroscopy. The [M(DA-salen)] complexes exhibit positive nonresonant nonlinear refractive indexes $\left(n_{2}{ }^{\mathrm{I}}\right)$ in the range $27.0-8.50 \cdot 10^{-21} \mathrm{~m}^{2} \mathrm{~W}^{-1}$ and nonlinear absorption coefficients $\left(a_{2}{ }^{\mathrm{I}}\right)$ within the range $1.80-26.0 \cdot 10^{-17} \mathrm{~m} \mathrm{~W}^{-1}$. The latter values correspond to less than $10 \%$ of the overall magnitude of the third-order susceptibility, $\left|\chi_{3}\right|$, which is the result of the absence of electronic transitions near $\lambda_{\text {inc }}=1064 \mathrm{~nm}$. For the group of $\mathrm{Ni}^{\mathrm{II}}$ complexes, the highest $n_{2}{ }^{\mathrm{I}}$ values are exhibited by the complexes with aromatic diimine bridges and large
\end{abstract}

$\pi$-electron delocalisation, which leads to intense electronic charge-transfer bands $\left(\varepsilon>16000 \mathrm{~mol}^{-1} \mathrm{dm}^{3} \mathrm{~cm}^{-1}\right)$ in the region $\lambda=275-500 \mathrm{~nm}$. The complexes that exhibit chargetransfer bands near $\lambda_{\text {inc }} / 2=532 \mathrm{~nm}$, also show the highest $\alpha_{2}{ }^{\mathrm{I}}$ values, a consequence of multiphoton absorption processes. For the group of $\mathrm{Cu}^{\mathrm{II}}$ complexes, the highest $n_{2}{ }^{\mathrm{I}}$ value is also observed by the complex that exhibits the most intense charge-transfer bands in the region $\lambda=275-475 \mathrm{~nm}$. Between $\mathrm{Ni}^{\mathrm{II}}$ and $\mathrm{Cu}^{\mathrm{II}}$ complexes with the same DA-salen ligands, those of copper show always higher $n_{2}{ }^{\mathrm{I}}$ values, indicating that NLO responses can also be fine-tuned by the metal centre.

(๔ Wiley-VCH Verlag GmbH \& Co. KGaA, 69451 Weinheim, Germany, 2006)

\section{Introduction}

During the last decade there has been a continuous demand for new materials capable of faster responses in optical information processing. ${ }^{[1]}$ More specifically, the search has been focused on materials possessing high nonresonant nonlinear optical (NLO) responses. This implies that the materials must have not only high nonlinear refractive indexes, but also small linear and nonlinear absorptions; otherwise the slow photothermal effects arising from absorptive processes dominate the desirable fast photorefractive effects. ${ }^{[2]}$

Molecules with high NLO responses must possess small differences between the ground and low excited states; the

[a] REQUIMTE/Departamento de Química, Faculdade de Ciências, Universidade do Porto,

Rua do Campo Alegre, 4169-007 Porto, Portugal

Fax: +351-22-6082959

E-mail: acfreire@fc.up.pt

[b] Departamento de Física, Faculdade de Ciências, Universidade do Porto, 4169-007 Porto, Portugal

[c] .INESC/Porto, Departamento de Física, Faculdade de Ciências, Universidade do Porto, 4169-007 Porto, Portugal

[\$] Current address: Department of Chemistry, University of Leicester, Leicester LE1 7RH, UK

[†t] Current address: Faculdade de Ciências da Saúde, Universidade Fernando Pessoa, Rua Carlos da Maia no. 296, 4200-150 Porto, Portugal corresponding electronic transitions should also correspond to strong absorptions and there must be a large difference between the dipole moments of the ground and excited states. $^{[3]}$ These properties can be accomplished by compounds with a $\mathrm{D}-\pi-\mathrm{A}$ structure, where an electron donor (D) group and an electron acceptor (A) group are placed away from each other in the molecule through a $\pi$-conjugated system, therefore creating a high asymmetry in the electronic density.

Organic compounds with extensive $\pi$-delocalisation have emerged as promising NLO materials instead of inorganic solids, due to their ultrafast NLO responses, good processability as thin-film devices and enhanced nonresonant NLO responses. ${ }^{[4]}$ More recently, transition metal complexes have appeared as an important alternative for the design of NLO materials, since the metal centre can impart important structural and electronic properties to the organic ligands, and consequently to the NLO responses. ${ }^{[5]}$ Among transition-metal complexes, those with porphyrins and their derivatives exhibit great potential application due to their twodimensional structures and unique electronic properties. ${ }^{[6]}$ The $\mathrm{N}_{2} \mathrm{O}_{2}$ Schiff-base ligands derived from salicyladehyde and diamines (generically named as salen ligands) can be used as alternative building blocks for the design/preparation of NLO compounds owing to their synthetic versatility relative to the introduction of electron donor/acceptor functionalities and creation of extensive $\pi$-delocalisation to in- 
duce large electron asymmetry. ${ }^{[7]}$ Furthermore, they can also coordinate several transition metal cations, in different oxidation states, which can additionally fine-tune the NLO responses.

The second-order NLO properties of metal complexes with salen-type ligands functionalised with electron donor and acceptor groups with a D- $\pi$-A structure have been extensively studied by Di Bella and Lacroix ${ }^{[8-14]}$ and some important conclusions have been presented on the relationship between complex molecular structure and second-order NLO properties. It has been shown that second-order NLO responses of salen-type complexes were related to the presence of intense low-energy metal-to-ligand, ligand-to-metal charge transfer and intraligand transitions. The importance of the metal centre in these complexes was shown in the surveys carried out by the same authors and others. ${ }^{[11,14,15]}$ Inclusion of metal centres in Schiff-base ligands was always accompanied by an enhancement of second-order NLO responses, compared to that of the free ligands and the role of the metal centre could be twofold, as it could act as both the donor of the D- $\pi$-A structure and/or as part of the $\pi$ bridging moiety.

With the work presented here we endeavour to extend the previous study on NLO properties of salen complexes to third-order and exploit the potential application of these compounds as building blocks for the preparation of materials with NLO properties suitable for ultrafast switching technologies. Several nickel(II) and copper(II) complexes with salen-type ligands functionalised with electron donor/ acceptor groups - denoted here by [M(DA-salen)] complexes (Scheme 1) - were investigated by the Z-scan technique and their nonlinear refractive index and nonlinear absorption determined and the relationship between molecular NLO properties and complex molecular structure exploited. To the best of our knowledge, this is the first study on third-order NLO properties of (salen)nickel(II) and -copper(II) complexes in solution, although recently, the third-order NLO properties of some related bis(salicylaldiminato) $\mathrm{Ni}^{\mathrm{II}}$ and $-\mathrm{Cu}^{\mathrm{II}}$ complexes were measured by a coupling Z-scan technique and degenerate four-wave mixing. ${ }^{[16]}$ The study presented here can also be the starting point for a survey of the NLO properties of electroactive films based on the same [M(DA-salen)] complexes, as previous works have shown that (salen)nickel(II) and -copper(II) complexes can be electropolymerized as electroactive films that exhibit interesting electrochromic properties. ${ }^{[17]}$

The potential application of these compounds/films in ultrafast switching technologies has determined the choice of the wavelength to study the third-order NLO responses, $\lambda_{\text {inc }}=1064 \mathrm{~nm}$, as the operating wavelength in ultrafast switching technologies is generally in the near infrared region $(\lambda=1000-1500 \mathrm{~nm}) .{ }^{[18]}$ It must be mentioned that very few of the organic materials reported so far are suitable for implementation in devices working in the near infrared. ${ }^{[4]}$ In fact, the absolute magnitude of the nonlinear refractive index can be enhanced by one- or two-photon resonant transitions when the compound has strong absorptions close to $\lambda_{\text {in }}(1064 \mathrm{~nm})$ and $\lambda_{\text {in }} / 2(532 \mathrm{~nm})$, and for the or-
[M(DA-salen $)]$ complexes

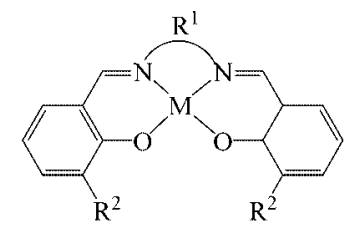

Complexes

$\mathbf{R}^{1}$

$\mathbf{R}^{2}$

1) $[\mathrm{Ni}(3$-pyrsalophenMe 2$)]$

2) $[\mathrm{Ni}(3-$ morfsalophenMe 2$)]$

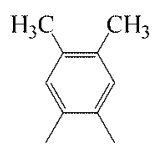

3) $[\mathrm{Ni}(3-\mathrm{MeO}$ salophen) $]$

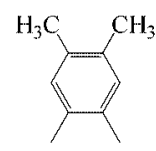

4) $[\mathrm{Ni}(3-\mathrm{MeOsaldiCN})]$

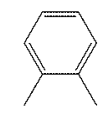

$\mathrm{CH}_{3} \mathrm{O}-$

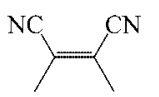

$\mathrm{CH}_{3} \mathrm{O}-$

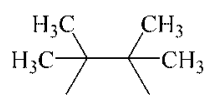

$\mathrm{CH}_{3} \mathrm{O}-$

5) $[\mathrm{Ni}(3-\mathrm{MeOsaltMe})]$

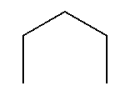

$\mathrm{CH}_{3} \mathrm{O}-$

6) $[\mathrm{Ni}(3-\mathrm{MeOsalpd})]$

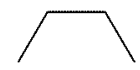

$\mathrm{CH}_{3} \mathrm{O}-$

7) $[\mathrm{Cu}(3-\mathrm{MeOsalen})]$

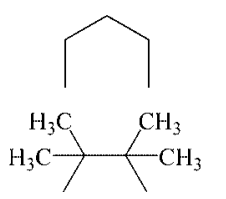

$\mathrm{CH}_{3} \mathrm{O}-$

9) $[\mathrm{Cu}(3-\mathrm{MeOsaltMe})]$

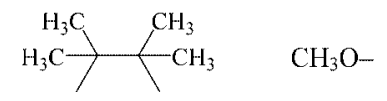

Scheme 1. Structures of $[\mathrm{M}(\mathrm{DA}-\mathrm{salen})]$ complexes, $\mathrm{M}=\mathrm{Ni}$ and $\mathrm{Cu}$.

ganic compounds with the largest nonlinear refractive index, strong electronic transitions are usually observed at $\lambda$ $=500-600 \mathrm{~nm}$, leading to strong absorption losses. ${ }^{[19]} \mathrm{In}$ this context, the attempt to produce new molecular compounds with the referred and desired properties still remains an actual area of research. The divalent transitionmetal complexes with salen ligands have square-planar geometries leading to strong electronic transitions (CT and intraligand) in the UV/Vis region and medium-intense $d-d$ bands in the far visible region; ${ }^{[20]}$ these electronic characteristics make them potential candidates for the preparation of materials with third-order nonlinear optical properties to be used in ultrafast optical communications.

\section{Results and Discussion}

The linear and nonlinear optical properties of the $\mathrm{Ni}^{\mathrm{II}}$ and $\mathrm{Cu}^{\mathrm{II}}$ complexes with DA-salen ligands summarised in 
Scheme 1 have been investigated as a function of the different combinations of the electron donor/acceptor groups introduced in the ligand in the 3-position of the aldehyde fragment (methoxy group, pyrrol or morpholine derivatives) and in the diimine bridge (several aromatic and aliphatic diimine bridges). These $\mathrm{N}_{2} \mathrm{O}_{2}$ tetradentate ligands with delocalised $\pi$-systems impart strong ligand fields leading to almost square-planar geometries and low-spin ground states for the metal complexes (for those that have more than one spin ground state), inducing high degrees of covalence/delocalisation within the metal-ligand bonds. The presence of these electronic properties, which are important in the design of molecules with high nonlinear optical properties, can be firstly surveyed from the study of the linear optical properties of the metal complexes.

\section{UV/Vis Spectra}

The UV/Vis spectra of $\mathrm{Ni}^{\mathrm{II}}$ and $\mathrm{Cu}^{\mathrm{II}}$ complexes with DAsalen ligands are very similar and present typically high intense bands $\left(\varepsilon\right.$ higher than $\left.1000 \mathrm{~mol}^{-1} \mathrm{dm}^{3} \mathrm{~cm}^{-1}\right)$ occurring at $\lambda<400 \mathrm{~nm}$, due to metal-to-ligand and ligand-to-metal charge transfer and intra-ligand transitions and one broad band in the visible region at $\lambda=500-650 \mathrm{~nm}$ with $\varepsilon$ values ranging from 70 to $400 \mathrm{~mol}^{-1} \mathrm{dm}^{3} \mathrm{~cm}^{-1}$, corresponding to the nonresolved $\mathrm{d}-\mathrm{d}$ transitions from the four low-lying $\mathrm{d}$ orbitals $\left(\mathrm{d}_{x z}, \mathrm{~d}_{y z}, \mathrm{~d}_{z^{2}}, \mathrm{~d}_{x^{2}-y^{2}}\right)$ to the empty (in the case of $\mathrm{Ni}$ ) or half filled (in the case of $\mathrm{Cu}$ ) $\mathrm{d}_{x y}$ orbital. ${ }^{[20]}$ This latter broad electronic band is not observed in the nickel complexes that have an extended $\pi$-system including the aldehyde moiety and the diimine bridge, as the more intense CT bands are shifted to higher wavelengths, therefore preventing its observation. This is a general trend that is observed for nickel and copper complexes with salen ligands that have an extended $\pi$-system and is a consequence of the high degree of $\pi$-delocalisation between the metal centre and the ligand, which in turn induces an increase in $\varepsilon$ values. The $\lambda_{\max }$ bands for all the complexes and the corresponding $\varepsilon$ values are summarised in Table 1 . The electronic spectra of nickel and copper complexes with salen complexes functionalised with methoxy groups are shown in Figures 1 and 2 as examples.

The energy of the broad band assigned to d-d transitions can provide a rough estimate of the equatorial ligand-field strength, since one of the electronic transitions comprised in the band envelope is $\mathrm{d}_{x y} \leftarrow \mathrm{d}_{x^{2}-y^{2}}$ and the energy associated with this transition is $10 D q-C \cdot{ }^{[7,20]}$ No comparison is possible between energies for $\mathrm{d}-\mathrm{d}$ transitions for the $\mathrm{Ni}$ complexes with aliphatic imine bridges (complexes 5 and $\mathbf{6}$ ) to those with aromatic imine bridges (complexes 1 to $\mathbf{4}$ ), as they are not observed in the latter complexes. However, for those with aliphatic bridges ( $\mathrm{Ni}$ and $\mathrm{Cu}$ complexes) it can be inferred that an increase in the number of bridging carbon atoms is associated with a small decrease in ligand field, as can be gathered from the lower energies of $d-d$
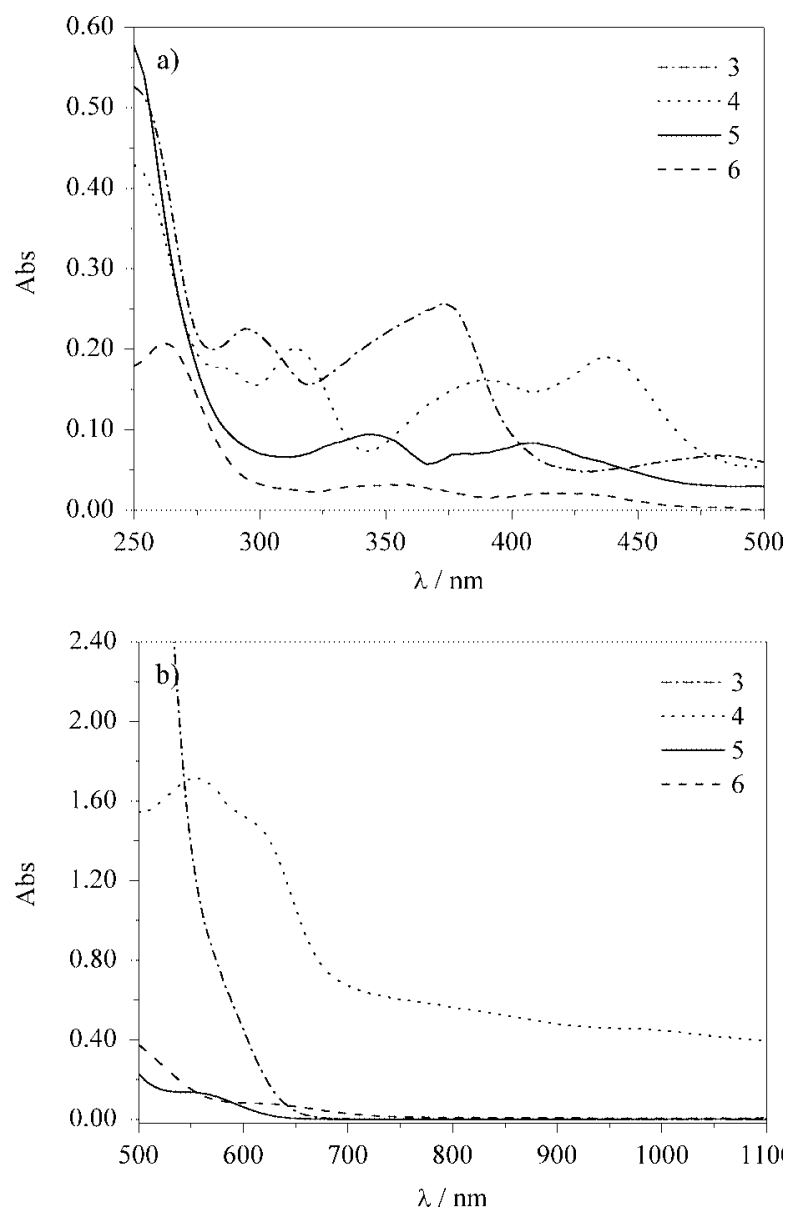

Figure 1. UV/Vis spectra of [Ni(3-MeOsalen)]-based complexes in solution recorded in the range: (a) $\lambda=250-500 \mathrm{~nm}$ (complex concentration $1 \cdot 10^{-5} \mathrm{moldm}^{-3}$ ) and (b) $\lambda=500-1100 \mathrm{~nm}$ (complex concentration $1 \cdot 10^{-3} \mathrm{moldm}^{-3}$ ).

Table 1. Electronic bands $\left(\lambda_{\max }\right)$ and respective absorption coefficients $(\varepsilon)$ for the $[\mathrm{M}(\mathrm{DA}-\mathrm{s}$-en $)]$ complexes.

\begin{tabular}{cl}
\hline Complex & $\lambda_{\max }[\mathrm{nm}]\left(\varepsilon\left[\mathrm{mol}^{-1} \mathrm{dm}^{3} \mathrm{~cm}^{-1}\right]\right)$ \\
\hline $\mathbf{1}$ & $254(42800), 294(16400), 312(18800), 376(22700), 447(14300)^{[\mathrm{a}]}, 471(9000)$ \\
$\mathbf{2}$ & $258(34400), 294(16100)^{[\mathrm{a}]}, 374(18800), 478(6000), 666(100)$ \\
$\mathbf{3}$ & $\left.294(22600), 396(19900)^{[\mathrm{a}]}, 356(23100)^{[\mathrm{a}]}, 372(25600), 482(6800), 560(1000)^{[\mathrm{a}]}\right]$ \\
$\mathbf{4}$ & $254(42100)^{[\mathrm{a}]}, 286(17800), 314(20300), 388(16200), 438(19100), 510(1400)^{[\mathrm{a}]}, 556(1600), 612(1400)^{[\mathrm{a}]}$ \\
$\mathbf{5}$ & $330(8400)^{[\mathrm{a}]}, 344(9400), 376(6900)^{[\mathrm{a}]}, 408(8300), 554(100)^{[\mathrm{a}]}$ \\
$\mathbf{6}$ & $262(20700), 346(3100), 358(3300), 416(2100), 630(100)^{*}$ \\
$\mathbf{7}$ & $278(34200), 360(9600)^{[\mathrm{a}]}, 372(10400), 378(10000)^{[\mathrm{a}]}, 574(400)$ \\
$\mathbf{8}$ & $280(28800), 366(7700)^{[\mathrm{a}]}, 372(7900), 378(7700)^{[a]}, 610(300)$ \\
$\mathbf{9}$ & $280(25900), 360(7700)^{[\mathrm{a}]}, 366(8100), 378(7700), 566(400)$ \\
\hline
\end{tabular}

[a] Inflections. 
transitions for the complexes with the 1,3-propanediamine bridge; this decrease must be due to an increase in the size of the ligand cavity. On the other hand, for $\mathrm{Cu}$ complexes the introduction of methyl groups in the ethylene bridge leads to a slight increase in ligand field strength due to the donor capacity of these groups. No trend in the values of $\lambda_{\max }$ of the d-d band was detected when comparison is made between the nickel and the copper complexes with the same ligands.
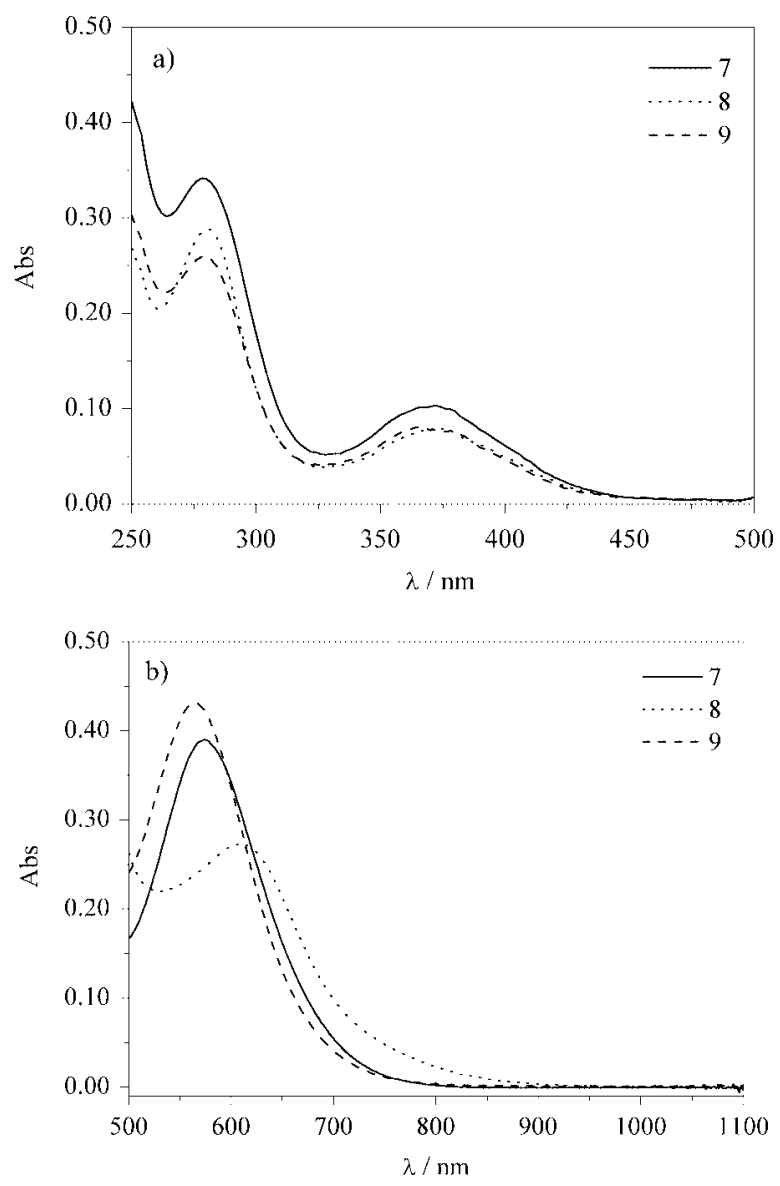

Figure 2. UV/Vis spectra of [Cu(3-MeOsalen) $]$-based complexes in solution recorded in the range: (a) $\lambda=250-500 \mathrm{~nm}$ (complex concentration $1 \cdot 10^{-5} \mathrm{moldm}^{-3}$ ) and (b) $\lambda=500-1100 \mathrm{~nm}$ (complex concentration $1 \cdot 10^{-3} \mathrm{moldm}^{-3}$ ).

Another key aspect to analyse in terms of the linear optical properties is the values of $\varepsilon$, for both types of electronic bands: d-d and charge-transfer bands. In this context it must be mentioned that the $\varepsilon$ values ( $\mathrm{d}-\mathrm{d}$ and $\mathrm{CT}$ bands) for the $\mathrm{Cu}$ complexes are always higher than those of the $\mathrm{Ni}$ homologues, and complexes with aromatic diimine bridges show higher values than those with aliphatic diimine bridges, with the complex 1 showing the most intense bands of the group of DA-salen studied in this work. These can be related to the degree of covalence in the $\mathrm{M}-\mathrm{L}$ bonds, and thus copper complexes will have a high degree of covalence when compared with the homologous nickel complexes.

\section{Z-Scan Measurements}

The Z-scan technique used to evaluate the NLO properties was developed by Sheik-Bahae et al. ${ }^{[21,22]}$ and is based on the transformation of phase distortion during beam propagation. By using a single Gaussian laser beam, the transmittance of a nonlinear medium is measured as a function of the sample position $(Z)$, measured with respect to the focal plane; further details on the Z-scan technique can be gathered from the literature. ${ }^{[21,22]}$ This technique requires relatively simple experimental apparatus, when compared with other common techniques, such as nonlinear interferometry, degenerate four-wave mixing (DFWM) and third harmonic generation (THG) and provides the direct measurement of both nonlinear refractive index and absorption coefficient, along with their sign, ${ }^{[23]}$ which allows the estimation of the third-order susceptibility coefficient $\left|\chi_{3}\right|$ in its real and imaginary components, respectively. Moreover, the measurement of third-order optical properties is not limited by restrictions in the system symmetry, which is an important advantage when compared with second-order techniques, which can only be used on noncentrosymmetric systems.

The experimental setup of the Z-scan technique was validated using carbon disulfide, which has been extensively studied in the literature. ${ }^{[2,21,22]}$ Figure $3 \mathrm{a}$ shows the $\mathrm{CS}_{2} \mathrm{Z}$ scan results and respective fitting curve obtained by the least-squares method: it shows the expected peak-valley curve with a pre-focal minimum followed by a post-focal maximum, which demonstrates a nonlinear refraction index with a positive sign. When compared with published works ${ }^{[21,22]}$ the curve shape allows us to ignore nonlinear effects arising from nonelectronic processes, mostly thermal effects, since the refractive processes depend on the temperature and the use of high-energetic lasers could be a contribution to the rise in the local temperature of the sample region where the laser is focused. Under these conditions, if the complexes present nonlinear refractive indexes, they will be only due to electronic processes. The nonlinear refractive index of $\mathrm{CS}_{2}$ was measured and is $1.09 \cdot 10^{-18} \mathrm{~m}^{2} \mathrm{~W}^{-2}$, which is very close to the reported value. ${ }^{[2]}$

All the complexes show a peak-valley curve with a prefocal minimum followed by a post-focal maximum, which demonstrates a nonlinear refraction index with a positive sign. The almost symmetrical shape of the Z-scan plots of the complexes shows that nonlinear refraction effects dominate any nonlinear absorption. In Figure $3 b$ a typical closed Z-scan result and the corresponding fitting curve are depicted for complex 3 .

The nonlinear refractive indexes of the complexes, $n_{2}{ }^{I}$, were calculated using the $\mathrm{CS}_{2}$ nonlinear refractive index by applying Equations (1) and (2), deduced from the theory inherent to the Z-scan technique ${ }^{[21]}$ and considering the experimental conditions unchanged during all the measurements performed. The nonlinear absorption coefficients, $a_{2}{ }^{I}$, were calculated using Equation (3), based on the BeerLambert law, in which $\Delta T_{p, v}$ is the difference of normalized transmittance peak-valley due to nonlinear refraction, 

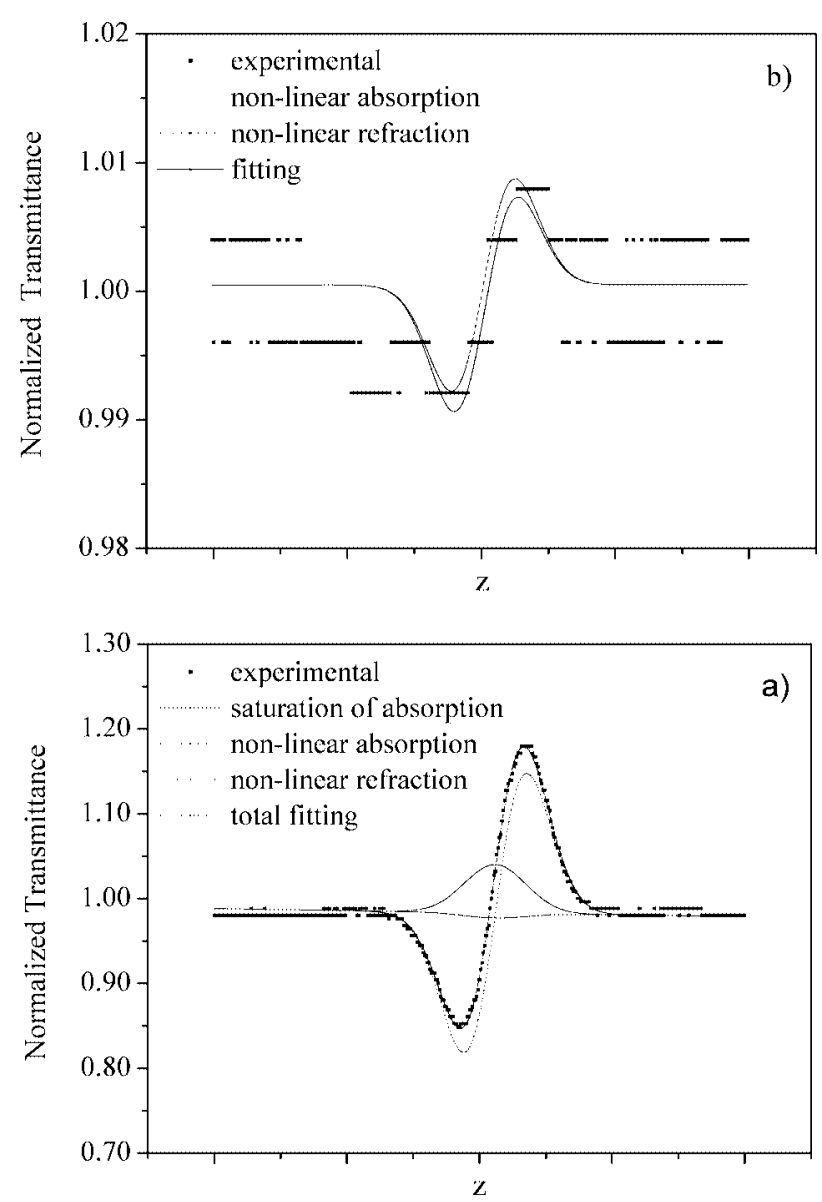

Figure 3. Closed Z-scan measurement at $\lambda_{\text {inc }}=1064 \mathrm{~nm}$; normalised transmission plotted as a function of sample position $z$ of: (a) $\mathrm{CS}_{2}$ and (b) a solution of complex 3 in $\mathrm{CH}_{3} \mathrm{CN}$.

$\Delta T_{v \text { (absorption) }}$ is the difference of normalized transmittance occurring in the valley due to nonlinear absorption. Both $\Delta T$ values were obtained using the least-squares method, $L$ is the sample length and $\alpha$ is the linear absorption coefficient.

$$
\begin{aligned}
& n_{2}^{I}(\text { sample })=\left(\frac{L_{\text {eff (reference) }}}{L_{\text {eff (sample) }}}\right) \times\left(\frac{\Delta T_{p, v(\text { sample })}}{\Delta T_{p, v \text { references })}}\right) \times n_{2}^{I}(\text { reference }) \\
& L_{e f f}=\left(\frac{1-e^{-\alpha L}}{\alpha}\right) \\
& \alpha_{2}^{I}=\left(\frac{\ln \left(1-\Delta T_{\text {vatiasomption })} \cdot e^{\alpha l}\right.}{I_{0}}\right)
\end{aligned}
$$

The nonlinear refractive index and nonlinear absorption coefficients allow the estimation of the third-order susceptibility coefficient, $\left|\chi_{3}\right|$, in its real and imaginary components, respectively using Equations (4) and (5); ${ }^{[2]} n_{0}$ is the linear refractive index, $n_{2}{ }^{I}$ is the nonlinear refractive index, $a_{2}{ }^{I}$ is the nonlinear absorption coefficient, $c$ is the light velocity and $k$ the magnitude of the wave vector, $k=2 \pi / \lambda$, where $\lambda$ is the wavelength.

$$
\begin{gathered}
\chi_{3}{ }^{(\text {real })}=2 n_{2}^{I} \cdot n_{0}{ }^{2} \cdot \varepsilon_{0}{ }^{2} \cdot c \\
\chi_{3}{ }^{(\text {imaginary) })}=\left(\frac{10^{8} \cdot n_{0}{ }^{2} \cdot \alpha_{2}^{I} \cdot \varepsilon_{0}}{(2 \pi \cdot k \cdot c)}\right)
\end{gathered}
$$

In Table 2 are summarised the normalized values for nonlinear refractive indexes $\left(n_{2}^{I}\right)$, nonlinear absorption coefficients $\left(a_{2}{ }^{I}\right)$ and the third-order susceptibility coefficient $\left(\left|\chi_{3}\right|\right)$ and its real and imaginary components; data is normalised for a complex concentration of $1 \mathrm{mmoldm}^{-3}$.

The complexes show nonlinear refractive indexes $\left(n_{2}{ }^{I}\right)$ at $\lambda=1064 \mathrm{~nm}$ in the range of $27.0-8.50 \cdot 10^{-21} \mathrm{~m}^{2} \mathrm{~W}^{-1}$ and nonlinear absorption coefficients $\left(\alpha_{2}{ }^{I}\right)$ within the range of $1.80-26.0 \cdot 10^{-17} \mathrm{~m} \mathrm{~W}^{-1}$. The contribution of nonlinear re-

\begin{tabular}{|c|c|c|c|c|c|c|}
\hline Complex & Solvent & $\begin{array}{c}n_{2}^{I} \cdot 10^{21} \\
{\left[\mathrm{~m}^{2} \mathrm{~W}^{-1}\right]}\end{array}$ & $\begin{array}{l}a_{2}^{I} \cdot 10^{17} \\
{\left[\mathrm{~m} \mathrm{~W}^{-1}\right]}\end{array}$ & $\begin{array}{c}\left|\chi_{3}\right|^{(\text {real }) \cdot 10^{34}} \\
{\left[\mathrm{~m}^{2} \mathrm{~V}^{-2}\right]}\end{array}$ & $\begin{array}{c}\left|\chi_{3}\right|^{(\mathrm{imag}) \cdot 10^{35}} \\
{\left[\mathrm{~m}^{2} \mathrm{~V}^{-2}\right]}\end{array}$ & $\begin{array}{l}\left|\chi_{3}\right| \cdot 10^{34} \\
{\left[\mathrm{~m}^{2} \mathrm{~V}^{-2}\right]}\end{array}$ \\
\hline 7 & $\mathrm{CH}_{3} \mathrm{CN}$ & 26.7 & 1.85 & 25.4 & 2.65 & 25.4 \\
\hline 1 & $\mathrm{CH}_{2} \mathrm{Cl}_{2}$ & 20.5 & 16.8 & 19.5 & 24.1 & 19.6 \\
\hline 9 & $\mathrm{CH}_{3} \mathrm{CN}$ & 17.1 & 8.18 & 16.3 & 11.8 & 16.4 \\
\hline 4 & $\mathrm{CH}_{3} \mathrm{CN}$ & 12.6 & 25.4 & 12.1 & 36.5 & 12.6 \\
\hline 3 & $\mathrm{CH}_{3} \mathrm{CN}$ & 12.6 & 4.63 & 12.0 & 6.66 & 12.0 \\
\hline 8 & $\mathrm{CH}_{3} \mathrm{CN}$ & 11.3 & 10.6 & 10.8 & 15.2 & 10.9 \\
\hline 6 & $\mathrm{CH}_{2} \mathrm{Cl}_{2}$ & 11.1 & 11.6 & 10.6 & 16.7 & 10.7 \\
\hline 2 & $\mathrm{CH}_{3} \mathrm{CN}$ & 9.53 & 4.07 & 9.09 & 5.85 & 9.11 \\
\hline 5 & $\mathrm{CH}_{3} \mathrm{CN}$ & 8.52 & 3.90 & 8.13 & 5.61 & 8.14 \\
\hline
\end{tabular}
fractive indexes and the nonlinear absorption coefficients to the overall magnitude of the third-order susceptibility

Table 2. Values of nonlinear refractive indexes $\left(n_{2}{ }^{I}\right)$, nonlinear absorption coefficients $\left(\alpha_{2}{ }^{I}\right)$ and third-order susceptibility coefficients $\left(\left|\chi_{3}\right|\right)$, real and imaginary components, for the $[\mathrm{M}(\mathrm{DA}-\mathrm{salen})]$ complexes. ${ }^{[\mathrm{a}]}$

[a] The complexes are displayed by decreasing values of $n_{2}{ }^{I}$. All values are normalised for complex concentration of $1 \mathrm{mmol}^{-3}$. The values of $\left|\chi_{3}\right|$ have been calculated with the following expression: $\left|\chi_{3}\right|=\sqrt{\left|\chi_{3}^{\text {reval }}\right|^{2}+\left|\chi_{3}^{\text {inutginasy }}\right|^{2}}$. 
coefficient is presented in Figure 4. Analysis of the plot indicates that in general, the imaginary part of $\left|\chi_{3}\right|$, associated with $a_{2}{ }^{I}$, contributes less than $10 \%$ to the overall $\left|\chi_{3}\right|$. Therefore, we can conclude that the NLO responses of [M(DAsalen)] complexes investigated in this work are mainly controlled by nonlinear refractive processes and this is an important result for our main objective of designing molecules with potential application for optical communications.

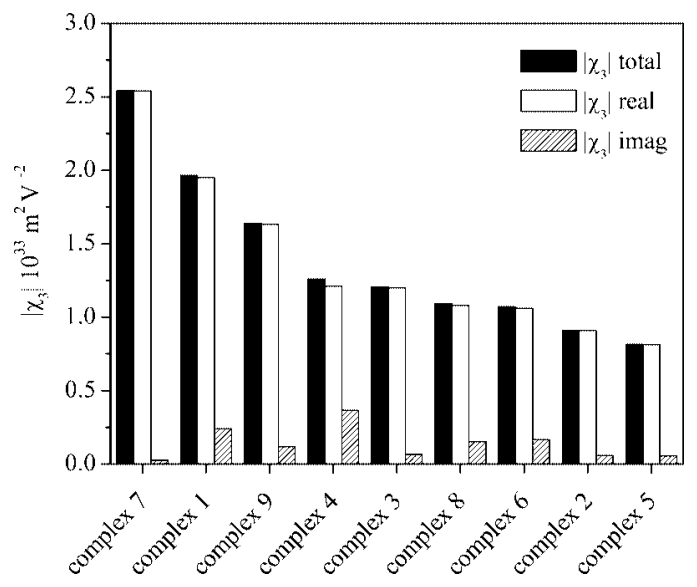

Figure 4. Different contributions for $\left|\chi_{3}\right|$ in $[M(D A-s a l e n)]$ complexes, $\mathrm{M}=\mathrm{Ni}$ and $\mathrm{Cu}$.

As mentioned previously, low values of $a_{2}{ }^{I}$ are compatible with the absence of electronic transitions near $\lambda_{\text {inc }}$ and $\lambda_{\text {ind }} / 2$. In fact, none of the complexes showed electronic transitions at $\lambda_{\text {inc }}=1064 \mathrm{~nm}$ (see UV/Vis spectra). Nevertheless, complexes $\mathbf{1}$ and $\mathbf{4}$ show two intense electronic transitions in the vicinity of $\lambda_{\text {ind }} / 2=532 \mathrm{~nm}$, the wavelength at which the double-photonic transitions occur, and thus are responsible for their highest nonlinear absorption coefficients.

The bis(salicylaldiminato) $\mathrm{Ni}^{\mathrm{II}}$ and $-\mathrm{Cu}^{\mathrm{II}}$ analogues ${ }^{[16]}$ of the complexes described in this work show a similar trend for their third-order NLO properties measured at $\lambda=$ $532 \mathrm{~nm}$ : values of $n_{2}{ }^{I}$ around $10^{-19} \mathrm{~m}^{2} \mathrm{~W}^{-1}$ and a small contribution of the nonlinear absorption to the overall $\left|\chi_{3}\right|$. This similarity can be attributed to the same geometry, ligand coordinating atoms and electronic structure of the metal centres in both types of complexes.

\section{Effect of the Substituents on the NLO Responses}

For the group of $\mathrm{Ni}^{\mathrm{II}}$ complexes functionalised with methoxy groups in 3-position of the aldehyde moiety, complexes 3 to 6 , the highest NLO responses are shown by complexes with aromatic diimine bridges with electron acceptor properties, [Ni(3-MeOsaldiCN)] (4) and [Ni(3-MeOsalophen)] (3). The highest NLO response of these complexes is the result of the presence of intense low-energy chargetransfer bands that are associated with a high variation of the transition dipolar moment vector. These are induced by the high degree of aromaticity, and the proper combination between the $\pi$-donor properties of the methoxy group in the aldehyde moiety and the $\pi$-acceptor properties of the imine bridges; on the contrary the $\sigma$-donor groups $\left(\mathrm{CH}_{3}\right.$ and $\mathrm{CH}_{2}$ ) in the aliphatic imine bridges of complexes $\mathbf{6}$ and 5 decrease the charge asymmetry and thus the NLO responses. Comparison between $\mathrm{Ni}^{\mathrm{II}}$ complexes with the same diimine bridge derived from 4,5- $\mathrm{Me}_{2}-1,2$-phenylenediimine and different substituents in the aldehyde, complexes 1 and 2, show that the former complex, which exhibits the largest number and most intense electronic bands is the one that presents the highest NLO response; in this case the proper combination between substituents to enhance the NLO response is the $\mathrm{CH}_{3} \sigma$-donor groups within the aromatic imine bridge and the pyrrol derivative in the 3-position of the aldehyde, that have electron-acceptor properties.

Within the $\mathrm{Cu}$ complexes, that are also functionalised with methoxy groups in the 3-position of the aldehyde, but have aliphatic imine bridges, the nonlinear refractive index of [Cu(3-MeOsalen)] (7) is considerably higher than those of [Cu(3-MeOsalpd)] (8) and [Cu(3-MeOsaltMe)] (9), following the same trend of the $\varepsilon$ values associated with the CT transitions. In this case, the NLO responses decrease with the increase in the number of $\mathrm{CH}_{3}$ or $\mathrm{CH}_{2}$ electrondonor groups in the aliphatic bridge, suggesting, as referred for $\mathrm{Ni}$ complexes, that methoxy groups still act as $\pi$-donor groups.

Between $\mathrm{Ni}^{\mathrm{II}}$ and $\mathrm{Cu}^{\mathrm{II}}$ complexes with the same DAsalen ligands, those of copper show higher $n_{2}{ }^{I}$ values, indicating that, besides the presence of DA electron groups within the salen ligand, NLO responses can also be finetuned by the metal centre. The increase in the NLO responses on going from (DA-salen) $\mathrm{Ni}^{\mathrm{II}}$ to $-\mathrm{Cu}^{\mathrm{II}}$ complexes have also been observed in the studies performed by Di Bella and Lacroix on the second-order NLO properties of similar complexes ${ }^{[1,12]}$ and in the study of the third-order NLO properties (at $\lambda=532 \mathrm{~nm}$ ) of the bis(salicylaldiminato) $\mathrm{Ni}^{\mathrm{II}}$ and $-\mathrm{Cu}^{\mathrm{II}}$ complexes. ${ }^{[16]}$ Some insights into a possible explanation can be gathered from their UV/Vis spectra, although the number of complexes to be compared is small.

The UV/Vis spectra of homologous $\mathrm{Ni}^{\mathrm{II}}$ and $\mathrm{Cu}^{\mathrm{II}}$ complexes, 5, 6, 8 and $\mathbf{9}$, in the range of $\lambda=250-500 \mathrm{~nm}$ (Figure 5a) show no significant differences in the $\varepsilon$ values of the CT bands, suggesting that the differences within the NLO responses may depend on other factors. Nevertheless, analysis of the spectra in the range $\lambda=500-1100 \mathrm{~nm}$, Figure $5 \mathrm{~b}$, where $\mathrm{d}-\mathrm{d}$ bands appear, show some interesting features: the $\mathrm{d}-\mathrm{d}$ bands of the $\mathrm{Cu}^{\mathrm{II}}$ complexes are more intense than those of the $\mathrm{Ni}^{\mathrm{II}}$ analogues, and the intensity differences are higher for the complexes with the tetramethylethylene bridge; the NLO response follows exactly the same trend. The differences in third-order nonlinear responses for these complexes with salen ligands with aliphatic bridges suggests that the metal centre displays an important role in the variation of the molecular transition dipole moment and thus in the NLO response. 

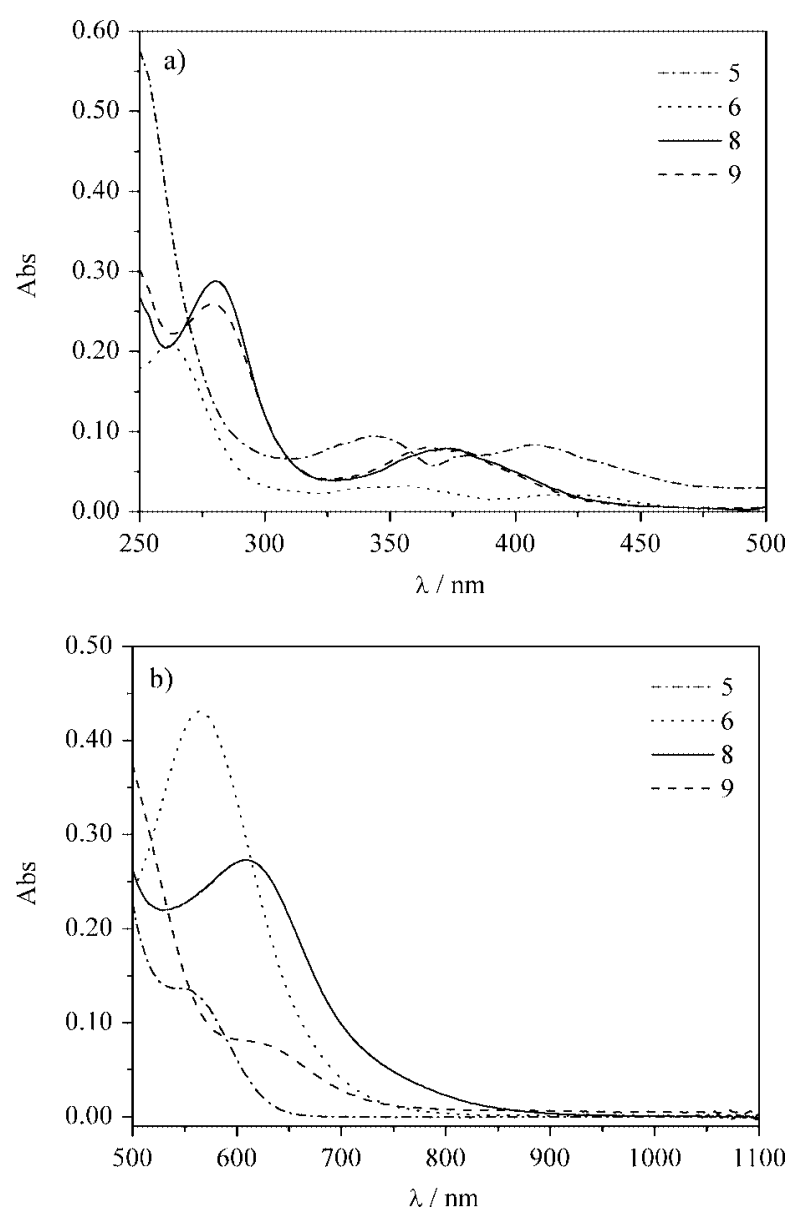

Figure 5. Comparison between $\mathrm{UV} / \mathrm{Vis}$ spectra of $\mathrm{Ni}^{\mathrm{II}}$ and $\mathrm{Cu}^{\mathrm{II}}$ with the same DA-salen ligands in the range: (a) $\lambda=250-500 \mathrm{~nm}$ (complex concentration $1 \cdot 10^{-5} \mathrm{moldm}^{-3}$ ) and (b) $\lambda=500-1100 \mathrm{~nm}$ (complex concentration $1 \cdot 10^{-3} \mathrm{moldm}^{-3}$ ).

It is worthwhile to mention that [Cu(3-MeOsalen)] (7) is the complex with the highest $n_{2}{ }^{I}$ of the compounds studied in this work, beyond those of nickel with high extensive $\pi$-delocalisation and efficient DA groups to create charge asymmetry. As the number of copper complexes used in this work is limited, no further conclusions can be made on the role of this cation in the NLO responses of Schiff-base ligands. Several $\mathrm{Cu}$ complexes with DA-salen ligands are now being prepared and their third-order NLO properties evaluated.

\section{Conclusions}

The linear and third-order NLO properties of some nickel(II) and copper(II) complexes with salen ligands functionalised with donor/acceptor groups, [M(DA-salen)], were investigated by combining electronic spectroscopy and the Z-scan technique.

The $[\mathrm{M}(\mathrm{DA}-\mathrm{salen})]$ complexes exhibit positive nonresonant nonlinear refractive indexes $\left(n_{2}{ }^{I}\right)$ in the range of 27.0 $8.50 \cdot 10^{-21} \mathrm{~m}^{2} \mathrm{~W}^{-1}$ and nonlinear absorption coefficients $\left(a_{2}{ }^{\mathrm{I}}\right)$ within the range of $1.80-26.0 \cdot 10^{-17} \mathrm{~m}^{2} \mathrm{~W}^{-1}$. The nonlinear absorption contribution is less than $10 \%$ of the over- all magnitude of the third-order susceptibility, $\left|\chi_{3}\right|$, which is the result of the absence of electronic transitions near $\lambda_{\text {inc }}$ $=1064 \mathrm{~nm}$ or strong absorption near $\lambda_{\text {in }} / 2=532 \mathrm{~nm}$, a consequence of the square-planar geometry of all the complexes coupled with a strong in-plane ligand field imposed by the DA-salen ligands.

The NLO responses follow the same trends observed for the number and $\varepsilon$ values of the metal complexes electronic bands in the UV/Vis region, and therefore UV/Vis spectroscopy has been shown to be an important tool to complement the study of NLO properties for [M(DA-salen)] complexes.

The combination of electron-donor/acceptor groups in [M(DA-salen)] complexes strongly affects the nature and value of NLO response; nevertheless, more important than the strength of individual donor and/or acceptor groups is the combination of both D/A groups to achieve a high nonlinear response.

The results presented in this work also show that replacement of $\mathrm{Ni}^{\mathrm{II}}$ for $\mathrm{Cu}^{\mathrm{II}}$ in DA-salen with aliphatic bridges leads to a significant improvement in the NLO response; however, no further explanations could be anticipated, because of the low number of complexes that have been studied. In future, we intend to prepare more $\mathrm{Cu}^{\mathrm{II}} \mathrm{com}-$ plexes with DA-salen and other metal complexes in order to better understand the role of the metal centre within the third-order NLO responses.

\section{Experimental Section}

Materials: All the solvents were obtained from Merck; nickel(II) acetate 4-hydrate and copper(II) acetate 1-hydrate were obtained from Riedel-de Haën, and diaminomaleonitrile from Fluka. The reagents 2-hydroxy-3-methoxybenzaldehyd, 4,5-dichloro-1,2-phenylenediamine, 4,5-dimethyl-1,2-phenylenediamine, 1,2-phenylenediamine, 1,3-diamino-2-propanol, ethylenediamine, 1,3-diaminopropane and 2,3-dimethyl-2,3-dinitrobutane were obtained from Aldrich; all the chemicals were used as received. The compound 2,3diamino-2,3-dimethylbutane was prepared by the method of Sayre, ${ }^{[24]}$ and 4-(ethoxymethyl)morpholine was prepared as described elsewhere. ${ }^{[25]}$ The DA-salen ligands were prepared by the standard method of refluxing an ethanolic solution containing stoichiometric amounts of the aldehyde and the diamines: ${ }^{[26]}$ typically $10 \mathrm{mmol}$ of the aldehyde was treated with $5 \mathrm{mmol}$ of the diamines, leading to yields in the range of $70-90 \%$. An exception was the preparation of the ligand 1,2-(4,5-dimethyl)phenylenbis(3-oxyethylpyrrole)salicylideneimine that was synthesised as described in the literature. ${ }^{[27]}$ Similarly, the respective complexes were prepared by the usual method of refluxing an ethanolic solution of the DA-salen ligand and the metallic acetate in stoichiometric quantities $^{[10,26]}$ (typically $5 \mathrm{mmol}$ of each reagent), leading to yields in the range of $50-80 \%$. An exception was the complex [Ni(3$\mathrm{MeOsaldiCN})$ ] (4), which was prepared by a procedure described in the literature. ${ }^{[12]}$

[Ni(3-pyrsalophenMe $)$ ] (1): ${ }^{1} \mathrm{H}$ NMR $\left(300 \mathrm{MHz}, \mathrm{CDCl}_{3}\right): \delta=7.78$ (s, $2 \mathrm{H}, \mathrm{CHN}), 7.56\left(\mathrm{~s}, 2 \mathrm{H}, \mathrm{H}_{\text {arom }}\right), 6.85-6.71\left(\mathrm{~m}, 8 \mathrm{H}, \mathrm{H}_{\text {arom }}\right.$ ), 6.33-6.20 (t, $\left.6 \mathrm{H}, \mathrm{H}_{\text {arom }}\right), 4.31-4.23\left(\mathrm{t}, 4 \mathrm{H}, \mathrm{CH}_{2}\right), 2.99-2.96(\mathrm{t}, 4$ $\left.\mathrm{H}, \mathrm{CH}_{2}\right), 1.90\left(\mathrm{~s}, 6 \mathrm{H}, \mathrm{CH}_{2}\right)$ ppm. $\mathrm{C}_{36} \mathrm{H}_{32} \mathrm{~N}_{4} \mathrm{NiO}_{6}$ (675.4): calcd. $\mathrm{C}$ 64.0, H 4.8, N 8.3; found C 64.0, H 4.8, N 8.2. 
[Ni(3-morphsalophenMe 2 )] (2): ${ }^{1} \mathrm{H}$ NMR (300 MHz, DMSO): $\delta=$ $8.78(\mathrm{~s}, 2 \mathrm{H}, \mathrm{CHN}), 7.95$ (s, $\left.2 \mathrm{H}, \mathrm{H}_{\text {arom }}\right), 6.75-7.49\left(\mathrm{~m}, 6 \mathrm{H}, \mathrm{H}_{\text {arom }}\right)$, 3.52-3.60 (m, $\left.12 \mathrm{H}, \mathrm{CH}_{2} \mathrm{O}, \mathrm{CH}_{2} \mathrm{~N}\right), 2.37-2.46\left(\mathrm{~m}, 8 \mathrm{H}, \mathrm{CH}_{2}\right), 2.30$ (s, $6 \mathrm{H}, \mathrm{CH}_{3}$ ) ppm. $\mathrm{C}_{32} \mathrm{H}_{36} \mathrm{~N}_{4} \mathrm{NiO}_{4}$ (599.4): calcd. $\mathrm{C} 64.1, \mathrm{H} 6.1, \mathrm{~N}$ 9.4; found $\mathrm{C} 63.1, \mathrm{H}$ 6.1, N 9.4.

[Ni(3-MeOsalophen)] $\cdot \mathbf{H}_{2} \mathbf{O}$ (3): ${ }^{1} \mathrm{H}$ NMR (300 $\left.\mathrm{MHz}, \mathrm{CDCl}_{3}\right): \delta=$ $8.22(\mathrm{~s}, 2 \mathrm{H}, \mathrm{C} H \mathrm{~N}), 7.71-6.30\left(\mathrm{~m}, 10 \mathrm{H}, \mathrm{H}_{\text {arom }}\right), 3.84(\mathrm{~s}, 6 \mathrm{H}$, $\mathrm{OCH}_{3}$ ) ppm. $\mathrm{C}_{22} \mathrm{H}_{18} \mathrm{~N}_{2} \mathrm{NiO}_{4} \cdot \mathrm{H}_{2} \mathrm{O}$ (451.1): calcd. C 58.6, $\mathrm{H} 4.5, \mathrm{~N}$ 6.2; found $\mathrm{C} 58.6, \mathrm{H}$ 4.6, N 6.3.

[Ni(3-MeOsaldiCN)] $\cdot \mathrm{H}_{2} \mathbf{O}$ (4): ${ }^{1} \mathrm{H}$ NMR (300 MHz, $\left.\mathrm{CDCl}_{3}\right): \delta=$ $8.08(\mathrm{~s}, 2 \mathrm{H}, \mathrm{CHN}), 7.01-6.74\left(\mathrm{~m}, 6 \mathrm{H}, \mathrm{H}_{\text {arom }}\right), 3.07$ (s, $\left.6 \mathrm{H}, \mathrm{OCH}_{3}\right)$ ppm. $\mathrm{C}_{20} \mathrm{H}_{14} \mathrm{~N}_{4} \mathrm{NiO}_{4} \cdot \mathrm{H}_{2} \mathrm{O}$ (451.1): calcd. C 53.3, $\mathrm{H}$ 3.6, N 12.4; found $\mathrm{C}$ 53.7, $\mathrm{H}$ 3.1, N 12.3.

[Ni(3-MeOsaltMe)] (5): ${ }^{1} \mathrm{H}$ NMR (300 MHz, $\left.\mathrm{CDCl}_{3}\right): \delta=7.50(\mathrm{~s}$, $2 \mathrm{H}, \mathrm{CHN}), 6.70-6.50\left(\mathrm{~m}, 6 \mathrm{H}, \mathrm{H}_{\text {arom }}\right), 3.80\left(\mathrm{~s}, 6 \mathrm{H}, \mathrm{OCH}_{3}\right), 1.40$ (s, $12 \mathrm{H}, \mathrm{CH}_{3}$ ) ppm. $\mathrm{C}_{22} \mathrm{H}_{26} \mathrm{~N}_{2} \mathrm{NiO}_{4}$ (441.2): calcd. C 59.9, H 5.9, $\mathrm{N} 6.3$; found $\mathrm{C} 59.9, \mathrm{H} 6.0, \mathrm{~N} 6.3$.

[Ni(3-MeOsalpd)] $\mathbf{2} \mathbf{H}_{\mathbf{2}} \mathbf{O}$ (6): ${ }^{1} \mathrm{H}$ NMR (300 $\left.\mathrm{MHz}, \mathrm{CDCl}_{3}\right): \delta=7.90$ (s, $2 \mathrm{H}, \mathrm{CHN}), 6.96-6.74\left(\mathrm{~m}, 6 \mathrm{H}, \mathrm{H}_{\text {arom }}\right), 3.91\left(\mathrm{~s}, 6 \mathrm{H}, \mathrm{OCH}_{3}\right)$, 3.77-3.71 (m, $\left.4 \mathrm{H}, \mathrm{CH}_{2}\right), 2.17-2.00\left(\mathrm{~m}, 2 \mathrm{H}, \mathrm{CH}_{2}\right)$ ppm. $\mathrm{C}_{19} \mathrm{H}_{20} \mathrm{~N}_{2} \mathrm{NiO}_{4} \cdot 2 \mathrm{H}_{2} \mathrm{O}$ (435.1): calcd. C 52.4, $\mathrm{H}$ 5.6, $\mathrm{N}$ 6.4; found $\mathrm{C}$ 52.0, H 5.6, N 6.3.

$[\mathrm{Cu}(3-\mathrm{MeOsalen})] \cdot \mathrm{H}_{2} \mathrm{O}$ (7): $\mathrm{C}_{18} \mathrm{H}_{18} \mathrm{CuN}_{2} \mathrm{O}_{4} \cdot \mathrm{H}_{2} \mathrm{O}$ (407.9): calcd. $\mathrm{C}$ 53.0, H 4.9, N 6.9; found C 53.5, H 5.3, N 6.9.

[Cu(3-MeOsalpd)] (8): $\mathrm{C}_{19} \mathrm{H}_{20} \mathrm{CuN}_{2} \mathrm{O}_{4}$ (403.9): calcd. C 56.5, $\mathrm{H}$ 5.0, $\mathrm{N} 6.9$; found $\mathrm{C} 56.6, \mathrm{H} 4.9, \mathrm{~N} 6.9$.

[Cu(3-MeOsaltMe)]·1.5 $\mathrm{H}_{2} \mathrm{O}$ (9): $\mathrm{C}_{22} \mathrm{H}_{26} \mathrm{CuN}_{2} \mathrm{O}_{4} \cdot 1.5 \mathrm{H}_{2} \mathrm{O}$ (473.0): calcd. C 55.9, H 6.2, N 5.9; found C 55.5, H 6.1, N 5.8.

Physical Measurements: The solution UV/Vis spectra of the complexes were recorded with a Unicam UV-2 spectrometer in the ranges of $\lambda=250-500 \mathrm{~nm}$ (complex concentration $1 \cdot 10^{-5} \mathrm{moldm}^{-3}$ ) and $\lambda=500-1100 \mathrm{~nm}\left(\right.$ complex concentration $1 \cdot 10^{-3} \mathrm{moldm}^{-3}$ ), using quartz cells with a $1-\mathrm{cm}$ optical path. The Z-scan technique measurements were carried out using a 6-ns pulse Nd:YAG laser $(\lambda=1064 \mathrm{~nm})$ with a repetition rate of $10 \mathrm{~Hz}$. The focal distance $f$ was $20 \mathrm{~cm}$, the energy per pulse $E$ in the focus was $0.2 \mathrm{~mJ}$, the beam radius at half-maximum in the focus $r_{1 / 2}$ was $1.5 \mathrm{~mm}$ and the aperture diameter $D$ was $2.2 \mathrm{~mm}$ (oscilloscope and photodiode). The spatial pulses were considered to be in the Gaussian transverse mode $\left(\mathrm{TEM}_{00}\right)$ and the sample is regarded as optically thin, because its length is small enough such that changes in the beam diameter within the sample due to either diffraction or nonlinear refraction can be neglected. The solutions were placed in a $1-\mathrm{cm}$ quartz cuvette which was fixed in a controlled translation stage moving along the $z$-direction. All the Z-scan measurements were performed with the finite aperture placed in front of the photodiode: closed Z-scan mode. The possibility of analysing the contribution of different NLO processes to the overall NLO response (nonlinear absorption and nonlinear refraction) by using only the closed Z-scan mode, is described elsewhere. ${ }^{[22]}$ This can be achieved because each process affects the transmittance through the aperture in a distinctive way: nonlinear absorption processes cause a symmetrical decrease of the transmittance with a minimum located in the focal point, linear processes are detected by a symmetrical rise in the transmittance around the focal point and nonlinear refractive processes are detected by the presence of a peak-valley profile, where the height and shape of the peaks are equal to the valley homologues, with an inflexion point placed at the focus. The fitting of experimental data was performed using a mathematical function composed of three different components that account for each phe- nomenon present within the sample: (i) a negative Gaussian associated with the nonlinear absorption coefficient, (ii) its first derivative which evaluates the nonlinear refractive index, ${ }^{[22]}$ and (iii) a Gaussian component with positive sign to evaluate linear processes. The experimental data fitting was obtained using least-squares methods. None of the solvents used in the preparation of the complex solution showed nonlinear optical behaviour; the complex concentrations used were within the range of 4.5-6.0 $\mathrm{mmol} \mathrm{dm}^{-3}$.

\section{Acknowledgments}

This work was partially funded by Reitoria da Universidade do Porto and Fundação Ilídio Pinho, Porto Portugal through Projecto de Investigação Científica na Pré-Graduação - 2004. We acknowledge the CLOQ Laboratory for the laser facilities. R. B. and C. S. thank Fundação para a Ciência e a Tecnologia (Portugal) for fellowships.

[1] M. Bass, J. M. Enoch, E. W. V. Stryland, W. L. Wolfe (Eds.), Handbook of Optics IV, Fiber Optics \& Nonlinear Optics, 2nd ed., McGraw-Hill, New York, 2001.

[2] J. G. Breitzer, D. D. Dlott, L. K. Iwaki, S. M. Kirkpatrick, T. B. Rauchfuss, J. Phys. Chem. A 1999, 103, 6930-6937.

[3] a) L. T. Cheng, W. Tam, S. H. Stevenson, G. R. Meredith, G. Rikken, S. R. Marder, J. Phys. Chem. 1991, 95, 10631-10643; b) L. T. Cheng, W. Tam, S. R. Marder, A. E. Stirgman, G. Rikken, C. W. Sprangler, J. Phys. Chem. 1991, 95, 1064310652.

[4] H. S. Nalwa, S. Miyata (Eds.), Nonlinear Optics of Organic Molecules and Polymers, CRC Press, Boca Raton, 1997.

[5] B. J. Coe in Comprehensive Coordination Chemistry II (Eds.: J. A. McCleverty, T. J. Meyer), Elsevier Pergamon, Oxford, U. K., 2004, vol. 9, p. 621-628.

[6] a) H. L. Anderson, S. J. Martin, D. D. C. Bradley, Angew. Chem. Int. Ed. Engl. 1994, 33, 655-657; b) H. S. Nalwa, A. KaKuta, A. Mukoh, Chem. Phys. Lett. 1993, 203, 109-113; c) H. S. Nalwa, A. Kakuta, A. Mukoh, J. Phys. Chem. 1993, 97 , 10515-10517.

[7] a) C. Freire, B. de Castro, J. Chem. Soc., Dalton Trans. 1998, 1491-1497; b) C. Freire, B. de Castro, Polyhedron 1998, 17, $4227-4235$.

[8] S. Di Bella, I. Fragalà, I. Ledoux, T. J. Marks, J. Am. Chem. Soc. 1995, 117, 9481-9485.

[9] S. Di Bella, I. Fragalà, T. J. Marks, M. A. Ratner, J. Am. Chem. Soc. 1996, 118, 12747-12751.

[10] S. Di Bella, I. Fragalà, I. Ledoux, M. A. Diaz-Garcia, T. J. Marks, J. Am. Chem. Soc. 1997, 119, 9550-9557.

[11] P. G. Lacroix, Eur. J. Inorg. Chem. 2001, 339-348.

[12] P. G. Lacroix, S. Di Bella, I. Ledoux, Chem. Mater. 1996, 8, $541-545$.

[13] S. Di Bella, I. Fragalà, Synth. Met. 2000, 115, 191-196.

[14] S. Di Bella, Chem. Soc. Rev. 2001, 30, 355-366.

[15] J.-B. Gaudry, L. Capes, P. Langot, S. Marcén, M. Kollmannsberger, O. Lavastre, E. Freysz, J.-F. Létard, O. Kahn, Chem. Phys. Lett. 2000, 324, 321-329.

[16] J. M. Floyd, G. M. Gray, A. G. V. Spivey, C. M. Lawson, T. M. Prichett, M. J. Ferry, R. C. Hoffman, A. G. Mott, Inorg. Chim. Acta 2005, 358, 3773-3785.

[17] a) M. Vilas-Boas, C. Freire, B. De Castro, A. R. Hillman, P. A. Christensen, Inorg. Chem. 1997, 36, 4919-4929; b) M. VilasBoas, C. Freire, B. De Castro, A. R. Hillman, J. Phys. Chem. $B$ 1998, 102, 8533-8540; c) M. Vilas-Boas, C. Freire, B. De Castro, P. A. Christensen, A. R. Hillman, Chem. Eur. J. 2001, 7, $139-150$

[18] B. J. Coe, Chem. Eur. J. 1999, 5, 2464-2471.

[19] F. Chérioux, A.-J. Attias, H. Maillote, Adv. Funct. Mater. 2002, 12, 203-208. 
[20] A. B. P. Lever, Inorganic Electronic Spectroscopy, 2nd ed., Elsevier, New York, 1984.

[21] M. Sheik-Bahae, A. A. Said, E. W. Van Stryland, Opt. Lett. 1989, 14, 955-957.

[22] M. Sheik-Bahae, A. A. Said, T. Wei, D. A. Hagan, E. W. Van Stryland, IEEE J. Quantum Electron. 1990, 26, 760-769.

[23] S. L. Gómez, F. L. S. Cuppo, A. M. Figueiredo Neto, Braz. J. Phys. 2003, 33, 813-820.

[24] R. Sayre, J. Am. Chem. Soc. 1955, 77, 6689-6690.
[25] H. Adams, N. A. Bailey, D. E. Fenton, G. Papageorgiu, J. Chem. Soc., Dalton Trans. 1995, 1883-1886.

[26] R. H. Holm, G. W. Everett, A. Chakravorty, Prog. Inorg. Chem. 1966, 7, 183-214.

[27] M. Andrade, C. Sousa, J. E. Borges, C. Freire, J. Phys. Org. Chem. 2005, 18, 935-940.

Received: January 10, 2006 Published Online: July 13, 2006 